\title{
Fashioning through materials: material culture, materiality and processes of materialization
}

Fashion is by nature temporary and ephemeral and its mutability makes it a difficult topic to define and to research. It is hard to grasp precisely because of the supposed speed with which it changes and the ways in which it comes to define the current moment which, by definition, rapidly becomes a moment in the past. But even though it is ephemeral it is indexed in material forms, things with materiality, so an empirical and theoretical focus on fashionable things would appear to be a suitable route through which to 'grasp' fashion. Approaches to studying fashionable objects evident in dress history place the material characteristics of cloth at their core, as does the anthropological literature on clothing's meaning across cultures. While these approaches offer possibilities for how to understand clothing as material culture, they often do not fully develop ways to consider specifically fashionable clothing as material culture. This article, and the Special Issue more widely, aims to address the dearth of research into fashion and materiality and in part we will address whether fashion can be considered as material culture.

Although it offers a promising a route into studying fashion, we are mindful of critiques of material culture studies that suggest a need to be more attuned to the lives and transformations of materials rather than just focusing upon objects (see Ingold, 2007) - such as an item of clothing. When considered through clothing then, we will consider whether material culture approaches tend to 'fix' the fashion moment, failing to address the flux, ephemerality and ambivalences (Wilson, 1985) that are seen to define what fashion is. This article explores and develops a tri-fold approach to this topic, exploring different approaches:

- fashionable things

- how materials make, constitute and dissolve fashions

- how fashions are materialized

These three approaches overlap, but offer a useful way of developing an approach to understand fashion's mutability and transience without presuming that we should either characterise fashion as 'immaterial', or that the materiality of things is just a 'carrier' of the meanings of fashion, as many semiotic approaches would assume (Barthes, 1985, Barnard, 2007) or that such meanings as accrue to clothes are necessarily deliberately transmitted by their wearer (Campbell 1996). In doing so, we build upon recent developments in the field of materiality and material culture (drawing on writers such as Ingold, 2010, Keane, 2005, Miller, 2007) and the emphasis found in this literature upon transformations and materials, to develop an approach to fashion. Setting out 
an agenda for approaching fashion through its materiality entails thinking about how we approach research (theoretically and methodologically) and what we are focusing upon (empirically). The introduction engages with theoretical approach and how this might be developed empirically and methodologically, as well as what the consequences are if we think about fashion materially. All of the articles in this Special Issue share an emphasis upon the processes of materialization, whether this is through focusing upon fashionable things, or upon the materials themselves.

\section{Fashion, fashionable and fashioning}

\section{Fashion}

Before moving on to consider what we mean by material culture and materialization, and to elaborate the three approaches outlined above, it is appropriate to discuss how we are approaching the concept of fashion. We have found it useful to start by thinking about the relationship between 'fashion', being 'in fashion' (or fashionable) and 'fashioning'. As a noun, 'fashion' implies the system of fashion that arose within, and is specific to, Western modernity, consequent on the mobility and anonymity that accompanied urbanization and mass production. This system entails particular social and technological infrastructures that enabled the design, manufacture and selling of clothes (Entwistle 2000, Breward and Evans, 2005). The fashion system has multiple different levels, including manufacture, design, retailing, catwalk shows, what people actually wear and the promotion of fashion through magazines. Technological developments accompany and incite changes in fashions, as supply chain communications such as EPoS technologies connect consumers and manufacturers. Consumers engage with fashion in new ways through the Internet, buying online and communicating different styles through blogs (Rocamora, 2011). Screen-based online technologies have made images of things central to the practices of fashion in a way that is supplementing and perhaps supplanting fashion's mediation by magazines. These mediations of fashion through images on blogs and catwalk shows form part of the spectacle of fashion, where fashion is something to be viewed and experienced.

This spectacular aspect of the fashion system can be understood in terms of Marxian commodity fetishism, which highlights the way that commodification obscures material relations, replacing them with 'mystical' ones. Whereas the 'glittering and blinding' discourse of fashion seen in catwalk shows and fashion magazines draws 'attention away from the substance of things' (Vinken 2005: 3), this notion of spectacle cannot be extended to fashion as worn by people every day. This dimension of fashion is best seen as an embodied material practice in Entwistle's sense (2000) - as material items of clothing are assembled and worn on the body. Far removed from the spectacle it may be, but this everyday practice is still fashion, one of the multiple different levels that 
exist within a fashion system that is so pervasive it reaches into all walks of life. Fashion's multiple levels imply the need for different perspectives and approaches to it. Fashion as it is mediated in magazines and increasingly the internet has been conceived of as an immaterial manifestation of fashion as it does not involved consumers trying clothes on their bodies, nor designers and manufacturers making concrete garments. However, rather than see this as necessarily immaterial, instead it is possible to see it as a form of materialization. The fashion show itself is a case in point: it could be seen as an ideal example of the spectacle of fashion, yet this spectacle is materialized through the lighting, the music and the ways in which the bodies move in the clothing. If we conceive of light, music, movement as material (Magaudda, 2011), then these all serve to make fashion material in particular ways - as the clothing is part of a multisensory mediation of a fashion show. When this approach is taken to fashion more broadly, then the mediation and creation of fashion through the internet also does not necessarily appear to be immaterial because the computer screen is a part of how fashion is experienced and made material, and has its own materiality. We explore these ideas further below.

\section{Fashionable}

The state of being 'in fashion' implies that a person wears clothes that are of the moment and has the requisite knowledges and cultural competences to both select the right clothing, and to wear it properly. Being 'in fashion' means assembling looks from a range of different items of clothing which may be newly acquired, or be reactivated from the back of the wardrobe (Woodward, 2007). Barnard (2007) has suggested that because of the pervasiveness of the fashion system, everything that people wear is therefore 'fashion' and while this usefully extends our understanding of fashion to all of what people wear, it does not do away with the distinction between 'fashion', as a system and the practice of being 'in fashion'. Rather, this distinction brings to the light certain complexities of being 'in fashion', for instance the question of who defines what is fashionable. There is often a discrepancy between what is defined as being in fashion' by fashion magazines and other media and what people themselves are wearing, and also what they consider to be fashionable (Woodward, 2009). A definition of what is 'in fashion' at any one moment differs between people, even in the same context because to be in fashion requires that people negotiate both with their own sense of style and that of their immediate communities, and with the fashion system. The definition of what is 'in fashion' also operates over a variety of timescales that are created by fashion as a system and by the personalized histories that intersect with the wearing of fashions, as several of the papers in this Special Issue demonstrate.

\section{Fashioning}


'Fashioning', whether in the sphere of production or of consumption, points towards a relationship between an individual and clothes, as either maker or wearer. From this restricted view of the relationship between people and things in fashioning, the relationship appears to be one-way - designers bring fashion objects into being; consumers create fashionable ensembles of clothes. While these types of actions on materials, or on ensembles of clothes do take place, they alone do not characterise 'fashioning'. From a relational perspective, it is networks of people and things that come to produce the meanings of fashion and that are entailed within the process of fashioning.

Actor Network Theory (hereafter ANT) is useful to help unpick how the categories of 'people' and 'things' that are in play, interact in 'fashioning'. By its principle of 'symmetry' (Callon 1986) neither would be given priority, nor indeed be seen as coherent or separate entities. ANT rejects the ontological splitting of materiality and meaning, and the prioritizing of meaning, instead materials and things are taken to be a pivotal part of the assemblages that come to constitute the social (Latour, 2005). Using this framework, 'fashion', or even a subfield within it, would be approached as an assemblage of human and nonhuman elements or 'actants'. The focus would be on the material and human arrangements, the materials, technologies and people that make up the phenomenon of fashion in question. This approach is not well developed within the field of fashion studies, (though see Entwistle and Slater, 2014 for a consideration of fashion models from an ANT perspective). This article is not suggesting that we should adopt an exclusively ANT approach to fashion, but instead that we can learn about how to think about different facets of fashion through its multiple material and human elements and their relationships.

Most significantly for this discussion of fashion's materialization, ANT has implications for how we think about agency. Seeing fashion in terms of the relationship between a maker and garments or between a wearer and their clothes, as above, implies that either a designer or wearer impart their meanings or associations onto the clothes. From an ANT perspective, agency emerges through the material/human assemblages that are taken to constitute the 'network'. In this respect, it mirrors the understanding of agency through materials that is present in a range of different formulations within the literature on material culture. A particularly useful framework is suggested by Gell (1998) who suggests that rather than agency being an attribute of people, it emerges in a web of people and things. Objects are part of the generation and actualization of the agency of people, and as such through their materiality can carry, or thwart people's agency. Applied to fashion, Woodward (2007) shows how the clothes in a successful outfit that a woman wears and feels comfortable wearing effectively externalize that person's intentions through their materiality. Conversely when outfits go wrong, the materiality of clothing can thwart women's intentionality - the leather skirt that they hoped would make them look 
sexy can make them look hot and sweaty instead. This can be extended to the relationship of designers to their work. A designer may want to embody certain characteristics in an item of clothing, but this is in part dependent upon the material propensities of the fabrics, and the styles, as is demonstrated in the case of shoe design in Braithwaite's article in this Special Issue.

This discussion of agency highlights what is at the core of material culture approaches to clothing, the centrality of the materiality of things - that is, how the material propensities of things impact upon how they are able to externalize particular cultural categories of identities. This is as true for making as it is for wearing (see for example Hoskins on weaving, 1989) and is seen in the diverse anthropological literature on material culture, which describes previous owners being 'carried' within clothing (Bayly, 1986), or gender and sexuality being externalized and contested through it (Hansen, 2004). Material culture approaches to clothing (particularly anthropological approaches) are brought together in two edited collections by Weiner and Schneider (1989) and Kuchler and Miller (2005). What emerges from Kuchler and Miller's edited collection is an attempt to direct some anthropological attention to the materiality of clothing in the context of the fashion system (see for example O'Connor, 2005). This literature offers a range of different approaches, ranging from a focus upon specific materials (such as O'Connor on Lycra), or collections of clothing (Woodward, 2007) or on the fibres of which clothing is made as items are made, break down and are recycled (Norris, 2005).

These approaches connect to some more recent shifts within the theoretical and empirical field of material culture studies, and can be usefully developed specifically in relationship to fashionable clothing. They will be discussed in detail in the next section, but are worth briefly flagging up here for their focus upon materials, and material transformations (these positions emerge from Norris' 2005 account). These developments do not replace, but can still be connected to, previous theories of material culture, seen through the example of Miller's reformulation of Hegel's theory of objectification (Miller, 1987) processes of self-construction and awareness that are seen to be material processes. In the context of clothing, to try on a garment and ask 'is this me' is to interrogate our sense of ourselves and to wear them and be comfortable in them (both physically and in social situations) is to change the self. Clothes do not represent us, but rather they 'are' us, because it is through material items of clothing and their properties that we interrogate who we are or can be (Woodward 2007). Implicit within this understanding of material culture as objectification is a sense of process and of transformation, equivalent to the notion of 'fashioning', which suggests how we can use approaches of material culture to look at fashionable clothing.

\section{Materials and meanings}


The relational nature of the fashion system's spectacular and material aspects, people's everyday negotiations with it to create a sense of being in fashion and the crossing between process of consumption and production that 'fashioning' implies all point towards questions of the agency of things. Things are both cultural and 'material', which in turn highlights the need here to consider the literature on materiality. Like the literature on fashion, research into materiality is multi-disciplinary and encompasses a range of core concepts. Just as we have discussed fashion, to fashion and fashionable, there is a parallel discussion around materials, materiality and material culture. However, unlike the fashion literature there is a lack of agreement over what these core concepts mean. Consequently, we will here not rehearse these debates in full, but rather explicate and develop the most useful ways of thinking about fashion in terms of materials, materiality, and also immateriality.

As noted above, it is now possible to discern 'objects of fashion', from particular items of clothing kept as treasured possessions, to 'virtual' representations of clothes, which are consumed as part of the process of identity formation through fashion. Fashion therefore can seem to present us with degrees of, and different kinds of materiality, and a process through which fashions, and being in fashion are materialized through the relational processes introduced above. This spectrum of materiality in relation to fashion is to some extent mirrored in the discussions about materiality itself that we outline below, which provides the rationale for delineating particular connections between fashion and the materiality literature.

Fashion is as an aspect of contemporary consumption that is emblematic of its materialism, both in the sense of the acquisition of goods and of the consumption of the physical inputs that make them up (materials, labour, energy). The goods we buy to clothe ourselves embody all these in large quantities. A focus on material, from a phenomenological perspective, has been present in the literature, articulated with a view of materiality as part of a theory of material culture. The most notable instance of this is Tim Ingold and Daniel Miller's dialogue on the relative prominence that should be given to matter material - as against meaning, in discussions of materiality (2007). This parallels the difference between accounts of fashion that concentrate on meaning and the expression of self-identity and accounts that focus on the material properties of fashion objects, as above.

Both Ingold and Miller draw on a rich literature in sociology, archaeology and anthropology including Bourdieu (1977), Gell (1998), Mauss (1934), Malafouris (2003), stating a desire to transcend the split between mind and matter, material objects and meaningful cultural surfaces, though they seek to do this from rather different perspectives and following different logical paths. Putting it crudely, Ingold takes an experiential and ecological approach, and Miller a dialectical and ethnographic one. Ingold seeks to transcend the hylomorphic 
approach to objects, which separates immaterial form from matter (2010a), tracing this division back to the Greeks. His approach to a critique of the hylomorphic imposition of abstract forms on passive matter is to emphasize the immanent properties of materials and the interweaving of forces that lead them to make up our world (2010b). One consequence of this approach is that he replaces a focus on 'objects' (which he takes to be passive and closed) with one on 'things' that arise through processes that bring together these forces through time and space. Miller's desire to 'entirely transcend the dualism of subjects and objects' (2005: 3) is also conceptualised in terms of processes albeit differently conceived to Ingold - particularly the dialectical process of objectification, which he works through in ethnographic examples as the previous section indicated.

For our purposes here, both approaches are relevant (and on close inspection their positions are far less opposed than they make out). Ingold's approach does justice to the sensorially based unfolding of individuals' relationships to their clothes which is evident in some of the articles in this special issue, though it denies distinctions between different degrees of materiality (2007:6). Indeed, Ingold argues against the entire concept of 'materiality', suggesting that it preserves a false distinction between what is 'material', which we can touch, and the 'immaterial', which is everything else. He appeals to James Gibson's (1979: 16ff) distinction between the ways that classes of material address each other as substance or medium, via surfaces. Distinctions between substance, medium and surface are contextually dependent - what is a substance for one organism may be a medium for another. This allows Ingold to demolish the material/ immaterial distinction by establishing that 'the surface of materiality, in short, is an illusion. We cannot touch it because it is not there. Like all other creatures, human beings do not exist on the 'other side' of materiality but swim in an ocean of materials' (2007:7).

Surfaces are central in developing an understanding of the materialities of fashion; not least an understanding of surfaces matters in debunking the dominant western ontology which sees surfaces - and by implication fashions - as unimportant, as it is the deep, immaterial 'inner' self that is important, rather than the surface which is superficial and transitory. This dichotomy between an inner self and an outer surface is also played out in the distinction between the material and the spectacular - presumed to be immaterial - facets of fashion. If we take Ingold's thinking then the boundaries between an inner person and outer surface, and between the materials of fashion and the immaterial are elided.

Miller shares Ingold's desire to collapse the distinction between mind and matter. However, in his introduction to a major collection of essays on the subject (2005), he builds the view of immateriality we refer to above in a distinction commonly found in religious culture between matter that is 
temporary and dissembling, and transcendent immaterial truth. He explores the seeming paradox that the more that religions strive for immaterial transcendence, the more they rely upon material things. He argues that a similar distinction can be seen in relationship to clothing and the presumed division between the surface of clothes that is 'false' because potentially dissembling, and the 'true' interior of an authentic self that is articulated across the membranes of fashion. Miller goes on to argue that if one is to take his notion of objectification then there can be no 'immateriality' as the very process of thinking about something entails it being materialized.

One of the dominant empirical approaches to fashion has been semiotic analysis - following Barthes The Fashion System (1985) - wherein the meanings of fashions are 'decoded'. These approaches have been applied to items of clothing itself (see Lurie 1992) but as Barthes himself notes, it is increasingly difficult to apply semiotic approaches to concrete items of clothing - not least because they seem to deny the very material stuff of fashion if the relationship between signifier and signified is random. This is strongly critiqued in Keane's 2005 discussion of the relationship between semiotics and materiality in which he focuses on Peirce's 'indexical sign' as an approach to meaning that both does justice to material, and to its circulation between matter and symbol. He explores the implications of this in reference to cloth among other things, which allows him point towards both the crafts of production in which the maker sees themselves indexed in their product, and consumption, in which we can see our biographies indexed in the wear on our possessions.

Miller defines his task in understanding materiality as to go beyond a 'vulgar' account of the artefact, to 'the ephemeral, the imaginary, the biological and the theoretical; all that which would have been external to the simple definition of an artefact' (2005: 4). This leads him to delineate a processual materiality that can encompass new forms, which also implies the questions about the distinction between the material and the immaterial we refer to above. One such new form is the screens which are increasingly pervasive as components of the fashion system, and through which the production and consumption of fashion is mediated. The computer/tablet/phone screen mediates the promotion and retailing of fashion as well as the experience of consuming it. Consequently, the materiality of screens that is discussed by Thrift (2005) is particularly relevant to thinking about how contemporary fashion is materialized. Screens could be taken to be simply surfaces for representation, and in respect of fashion, their surfaces simply as part of the mediatising apparatus that sits between immaterial fashion, and fashions that are worn. However, they have claim to materiality of their own. They are both windows onto a world, or many worlds, and material entities that are part of our everyday accoutrements - and which in some cases such as smart phones comprise objects that we wear. Further than this, in the way they both rely on, and generate, light, they function 
as part of our personal 'lightscapes' (Bille and Sorensen, 2007, Maffei and Fisher 2013). Screens are both portals to a network of communication and material objects. This dual material/ immaterial nature means they mirror some of the qualities of fashion that we are bringing out here - they function analogously as 'telescopes', as 'jewellery' (Fisher 2013) and also as mirrors. They are things that we see through and things that we look at, and things we see ourselves in.

Agnes Rocamora (2011) in work on personal fashion blogs has developed the idea of the screen acting as a kind of mirror, as bloggers present images of themselves on their blogs and are 'reflected back' through the images and comments that followers post. Her ideas can be extended even to consumers who both see their own mirror image in the shininess of the screen and also may be effectively imagining 'is this me' through the images on the screens. Rocamora draws on Manovich (2001) who traces the genealogy of screens from flat ones designed to be looked at as a screen straight in front of you, to ones that can be moved about and have real time images and videos on them. This could now be extended to the portability of phones and tablets. Touch screens add a materiality of touch to the visuals of fashion on screens, but this touch is never the touch of the actual clothes. Blogs or social networking sites, and online magazines and stores' own sites present a fashion that is mobile as videos capture fashion in motion, interactive as we can make things bigger, get close up to see something of the materiality of clothing. As such, even the supposedly immateriality of fashion that is reduced to screen-images is in fact a multisensory presentation - not the same as the materiality of items of clothing on our body, but nonetheless still material.

It is our contention that in the context of fashion, an appropriate position on materiality must treat the cultural and material elements present in fashion with the symmetry advocated in actor network theory. Here, we go along with Miller's desire not to 'enthrone' materialism or objects in place of 'culture, society and representation'. But given how fashion studies have developed and the lack of focus upon materials, it is appropriate to follow Ingold and ensure a focus on material characteristics, and the practices that materialize fashion. As Carl Knappett (2005: 21) puts it, '...just as archaeologists find it difficult seeing through the material to the social, so it seems the ethnographer or sociologist struggles to see through the web of social relations to materials and their properties', which implies a symmetrical approach to both the cultural/ symbolic elements in fashion and the agentic elements of clothes is needed to uncover the cultural implications of the material that makes up the surfaces that individuals present to the world. This honours the necessarily recursive character of the relationship between people and the materials of fashion as it unfolds over time, which connects to the process of 'fashioning' that we 
introduced in the first section that, we argue, constitutes the empirical and also theoretical focus for carrying out research into fashion and materiality.

\section{Methods and Approaches}

A focus upon process entails thinking about how we might progress with research into this field. If we are suggesting that the material and cultural are not separate but co-constitutive, then when approaching fashion we are similarly suggesting that the material is integral to what we are looking at. The focus of such research can take three trajectories:

- fashionable things

- how materials make, constitute and dissolve fashions

- how fashions are materialized.

These three approaches are not mutually exclusive but overlap and form a useful route into thinking about how the fashion researcher can proceed adopting the approach that we are outlining in this article. Approaching fashion as material does not restrict research to one domain of fashion, but can be applied to manufacture, design, retail and consumption. The main areas within which we explore this are consumption and design, arising from our own research areas, and the focuses of the paper within this Special Issue.

\section{Fashionable Things}

Dress historians have focused empirically and methodologically upon the deconstruction of particular items of clothing. Although not always explicitly concerned with fashionable things, they often use object based deconstruction to look at how particular fashions were materialized through being made, and also being worn. Whilst such approaches have been criticised for being overly descriptive, there is much to learn from their material attentiveness, and in the last 10 years there has been a sustained attempt to develop an understanding of cultural categories such as gender or social class (see Taylor 2004). This material attentiveness has always been present in anthropological work on clothing, where the materiality of the clothing is central to its cultural meanings. There have been attempts to bridge the divide between object-based analysis and cultural studies influenced approaches through material culture approaches to clothing (Kuechler and Miller, 2005). However, as O'Connor notes (2005), most of the literature on fashion and fashionable clothing still fails to engage sufficiently with the materiality of clothing, as if when clothing is part of the fashion system it ceases to be material. Whilst there are exceptions to this approach, mainstream writing on fashion is not centrally concerned with the materiality of fashionable clothing. 
One such exception is the Global Denim Project, which aimed to address why denim jeans are such a widely worn item of clothing in the contemporary world, and ask what understanding this tells us about the world we live in (Woodward and Miller 2007, 2011). To return to the definitions of different facets of fashion outlined earlier, denim jeans themselves may be part of 'fashion' in terms of a system, but may not always be 'fashionable'. Fashion is always material, yet material things are not always fashionable. The fact that denim jeans are such a globally ubiquitous item of clothing means that understanding them allows us to explore the consequences for the fashion industry of them being so widely worn. It has implications for how fashion production is organised materially (Chakravati, 2011), how designers are forced to work 'with' denim as there is no sign of a waning in the desire consumers have to blue jeans, and how consumers are able to buy jeans that will make them feel comfortable. Focusing on one fashionable thing like jeans allows an exploration of the interconnections of the global fashion industry and the different materializations of the generic and personal in different cultural contexts. Although it is an example of a focus upon a fashionable thing, several projects within it focused upon the materials of denim as it is broken down and recycled (see Olesen, 2012) which fits with the other approaches to fashion that we are suggesting.

Before moving on to these approaches, it is important to highlight that focusing upon the fashionable object entails a shift away from semiotic approaches which see meaning arising from free-floating signifiers. As Breward notes, such approaches see clothing as 'temporary receptacles of floating meanings' (2003: 63), which attach themselves to clothing transitorily. In part this is due to what Miller (2005) argues is the dominant understanding of the relationship between immateriality and materiality - that of representation. If clothing 'represents' a fashion, a person or an association such as femininity, then the materiality within these modes of thinking is not relevant but merely an arbitrary means of representation. Thinking about the meanings of clothing as simultaneously material and symbolic is highlighted in Sherlock's article in this Special Issue. Using the example of shoes as a fashion object through the example of wearers of Clarks Originals, she argues that semiotic approaches are not sufficient on their own, but need to be seen in tandem with material approaches to the 'affordances' of shoes. Her article effectively manages to conjoin an understanding of the meanings and associations of the shoes with the material possibilities of the fashionable object. Through the object, wearers are fashioning an identity, which is both anchored in a particular fashion moment and period, yet simultaneously highlights the endurance of a style over time.

\section{Materials - creating and dissolving fashions.}

The meanings of a fashion object are therefore in part afforded by the materiality of, in Sherlock's example, the shoe. Such articles form an important redress to semiotic accounts which do not pay heed to the materiality of the 
fashionable object. A key facet of an approach to the fashionable object is to understand the multi-sensorial - that is the tactile, the visual, and the material (Howes, 2005). Whilst there has been a shift towards looking at embodied fashion phenomenologically (in the wake of Entwistle's account, 2000), there has been a lack of focus upon ways of wearing and making fashionable things is multi-sensory, and where the material is central. Materials have been sidelined in accounts of fashion and its meanings, as exemplified by Barnard's assertion (2007) that although the natural sciences are central to the development of fabrics and materials, this is not centrally relevant to cultural and personal meanings. We would argue that clothing gets its meanings from its materials and materiality. Materials have only been a focus in discussions within the natural sciences or within the social sciences when they are concerned with innovative fabrics or fibres, as for instance in Küchler's review of advances in electronic textiles (2005: 212ff).

Braithwaite's article goes some way towards addressing this issue in her case study of shoe designers and the process of design as the fashioning of shoes. It is clear from her article that materials, such as leather, are not just a medium for the realization of designer's ideas, but the very catalyst for these ideas and therefore their creativity. The designers in Braithwaite's ethnography are 'imagining with materials' which dovetails with Miller's understanding of objectification - 'to conceptualise is to give form and to create consciousness' (2005: 21). Looking for materials ('looking' with the hands) is an act of idea generation for the shoe designers Braithwaite worked with. The process of materials being transformed into shoes is both physical and conceptual, it is a process of ideas generation and creativity. The article highlights an interesting paradox between the ways in which designers are fashioning shoes (in the sense of fashioning their identity as fashion designers and also making fashionable things), and their disavowal of 'fashion' as a system. The feature of the fashion system that they are disavowing is its commerciality, which they equate with a lack of creativity, although in practice it is the basis for the availability and circulation of materials through which they form their ideas.

As we have suggested above, there is a need for more research into fashion that focuses on materials; Klepp and Hebrok's article specifically addresses this need. The material at the centre of their project is wool, and they explore the complexities of its material properties in a register that is ordinarily seen to be in the domain of textile technology. However, they highlight the need to remain aware of these properties when we consider consumers' attitudes to wool as it manifests itself in physical engagement with materials because, as their results show, these properties are simultaneously material, experiential and cultural.

Holmes' paper focuses upon the materiality of hair. Hair is ambiguous in terms of how it is categorised, we can think of it as a kind of material but we also think of it as part of our bodies, and as a (potentially fashionable) thing, such as a 
hairstyle. This ambiguity highlights that the relationship between materials and fashionable things is not fixed but rather transient and there is much to be learnt by focusing upon the relationship between the two - the processes that render materials into fashionable things. Her paper usefully considers how the materiality of hair makes it both an ideal carrier of fashion due to its apparent malleability (it is easily cut and dyed and restyled), at the same time as its materiality means that it refuses fashions (for example curly hair may resist certain styling practices). She shows that fashions are not just the result of women passively submitting to fashionable hair-dressing, but are carried in the 'palimpsest' of hair, where the currently fashionable co-exists with material traces of previous 'fashionings'. The curious temporal stratification of fashion in the material of hair that Holmes describes, which is both of the body and carries meanings that are fashioned in its material, brings together a number of the strands and elements we have teased out in our discussion so far. It may be somewhat easier to see the ways these elements cross over through hair than it is in the case of clothes because it is a particular sort of 'fashion object' attached to and part of the body and necessarily fashioned 'in situ'.

\section{Fashion and the processes of materialization.}

One of the aims of this article and the special issue as a whole is to start to problematize and probe the assumed connection between fashion and immateriality. This association comes in part from the way that fashion is characterised as fleeting and changing; however, fashion is still materialized in clothing and even its seemingly less material manifestations - through screens and in the fugitive spectacle - have their own materiality. In the section of this article on materials and meaning we have started to explore theoretically how we might start to challenge this association, through Ingold's suggestion that there is no separate immaterial domain. The only convincing case to be made for the immateriality of fashion can be found in Kaori O'Connor's work on Lycra (O'Connor, 2005). As Lycra products were not made for middle aged women in larger sizes, this consumer group of 'Baby Boomers' was not able to buy products that might have allowed them to construct their identities in a different way. The fact that these things were not made for this consumer group is significant and O'Connor notes that there is little research on fashionable things that are not made and why they do not materialize. Fashion here is immaterial as these products could have existed, but did not.

In much of the fashion literature there is an implicit assumption that fashion itself is immaterial; this is present in the discussion of how fashion is materialized in clothing, implying that fashion somehow exists outside of, and precedes its existence in the form of, clothing. At the level of fashion design this is analogous to seeing ideas as somehow immaterial and preceding the fashioned garment, as in the hylomorphic model for design that Ingold critiques. Yet as Braithwaite's article in this volume highlights, material agency can be a 
key element in the process of generating ideas, rather than the means through which an immaterial idea is made material. In the introduction to the Material Culture Reader, Buchli suggests that rather than looking at material culture, we should be focusing upon 'materialising and transformative processes' (2001, p15). If we place the process of materialization, at the heart of our understanding, it allows us to understand the complex materialities and processes of change and transformation that characterize fashion. Given its ephemerality (even if we are considering longer term trends), this may be a more useful approach than to think about fashion as 'material culture', which has been criticized for implying a false stasis and coherence (Ingold, 2007). Focusing upon materialization as a process allows us to incorporate both the longer term relationships people have to fashionable garments, and also the possibilities of change and fluidity that are part of the ways in which fashion moves with the times.

This also strongly dovetails with the discussions in the first section of this article on thinking about fashion itself as a process - 'fashioning' rather than just as 'fashion'. There has been previous work on fashion as process yet less on how this is a material process. Thinking about fashion as a process of materialization rather than discrete fashion objects, is a way to focus upon how fashions come into being, how things are worn, fall apart and are then recycled. It offers a means to connect the discrete fields of fashion. It also allows us to explore issues of temporality that are at the heart of how we define fashion, whether this is seen as being of the current moment, defining a historical era, or a longer burning fashion trend. There are numerous routes this approach might take us, and here we would like to suggest three possible approaches to researching fashion as a process of materialization.

\section{Materialization of a fashioned garment.}

This kind of approach is exemplified in Braithwaite's article in this volume, as the genesis of fashion garments is explored as a material process. However, this approach can be extended beyond the genesis of garments in the domain of production or of design, into the sphere of consumption as garments move from being made, to being imaged on the screen as part of the fashion spectacle, to being worn on bodies and sitting in wardrobes. While this is a process of materialization, it is also a process of dissipation as the things wear down, are discarded and amass in landfill or are broken down into fibres and recycled as material. The trajectories are not straightforwardly linear or circular, and cannot just be seen as a shift from being made and therefore made material to gradually falling apart. There are staging points in these paths that bifurcate and cross over under the influence of the myriad potentials in the material and actions by the agents they encounter on the way. 
Items of clothing are imaged, transported, stored in a warehouse, ordered by someone, then as the item arrives in their house it is simultaneously seen by someone else on a screen or uploaded as an image onto Facebook as a new purchase. This process can be understood as different kinds of materializations that follow on from each other or that co-exist, rather than as a switch between material and immaterial forms - at the end of their lives clothes may enter another cycle of re-materialization as they are re-cycled. This more complex view of materialization can also be applied to an understanding of fashion trends, which could be seen through this approach as a series of materializations; such as the boot cut jeans, followed by skinny jeans, followed by high waisted ones. Seeing fashion as a series of materializations would offer a new way of thinking about some of the implications of fashion production and consumption as it currently stands in terms of sustainability (see below for full explication of this).

\section{Materialization of an outfit.}

Materialization can be approached as a process of material transformation through which a garment goes, yet we can also adopt it as an approach to fashioning the self through consumption. If we see fashion as the assemblage (Woodward, 2007) of new items with old items, or even of several new items together, then an outfit is the coming together of different times of clothing and thus of multiple histories into a temporary fashion constellation. These histories are also material as Ingold has suggested - materials are not just 'attributes' but also 'histories' (2007: 15). As outfits are comprised of different items of clothing, different materials intersect in constructing the fashionable. One outfit may include the stretch of elastane, the lightness of cotton or the softness of cashmere. These attributes of materials are not given, stable properties, but ones that come from how garments are made as well as the cultural and personal connotations they accrue through experiences of wearing and dealing with different fibers and fabrics.

\section{Material temporalities.}

It is implicit in both of the approaches just discussed that a focus upon materialization entails thinking about fashion as a process, as transformation and flux to understand its temporality. Temporality is pivotal to how we understand fashion, and here we would like to suggest that by focusing upon fashion as a process of materialization allows a new way of thinking about the relationship between clothing, fashion and temporalities.

Acknowledging Ingold's argument for the need to focus upon flux and transformation in materials and in turn the 'things' in which they reside, given the temporality of fashion, there is a disjuncture between material life and the 
life of a fashionable thing. From this perspective, the temporalities that emerge through looking at fashion as materialization are:

- the life of a fashionable thing (broadly conceived as a trend),

- the material life of the object before and beyond this,

- the dynamic ways in which things may move in and out of being fashionable over time.

The last point highlights the need to consider temporal endurances of the material as well as constantly shifting fluxes in fashions. The complex intersection of material and fashionable temporalities is a focus of two of the articles in this Special Issue. Firstly, in Botticello's article, fashion is not a system of rapidly changing styles that replace each other, but instead is seen in terms of longer-term shifts that intersect with individuals' biographies. By focusing upon the materiality of clothing through these longer-term shifts, Botticello is able to offer an understanding of fashion not as 'surface' but as depth - that is, people are able to articulate a sense of who they are through fashions, their 're-purposing' of material materializes their biography. These examples demonstrate that thinking about 'fashioning' through materialization confirms the agency and intentionality of consumers.

The relationship between personal biography and the slow-burning, longerterm temporalities of fashion is one that is explored in Slater's paper. She looks at the relationship between items that in one instance have been kept, and in another only exist in memory, from a previous time in two women's lives. In one case, things are kept to make a memory possible, as the material index of it, and in the other the clarity with which material details are recalled are what allows the memory to last. This example of fashion existing for the memory of an individual, demonstrates a further level of the complex relationships between temporality, fashion and materiality. It is not a simple equation that things that are kept and last are material and those that have been discarded or that have fallen apart are not. Here there is an agency in memories of materials, as well as actual materials that allow memories.

\section{Conclusions - the consequences of fashion:}

This article has navigated the complicated relationship between fashion and materiality; although almost entirely separate fields of literature exist for material culture and for fashion (with some attempts to explicitly consider fashion and materiality), we have argued that fashion is always material. There is a quite deep rooted assumption that fashion is immaterial, yet fashion requires material things - clothing. However, rather than see fashion as an immaterial force that temporarily resides in items of clothing, instead we have argued that fashion is always materialized. Instead of seeing some facets as 'immaterial' we consider fashion as consisting of different kinds of 
materialization (such as the images on a screen, the way clothing in a fashion show catches the lights of the cameras, as well as an item of clothing).

This approach is important to understanding fashion, as fashion is not a single thing; we have developed a framework to think about this, by seeing fashion as a noun, a verb and a state of being. A particular emphasis in our article has been upon the processes through which fashion is materialized as we consider how materials are involved in the process of fashioning. By focusing upon fashioning as materialization(s) it is possible to see those processes across production, consumption and disposal (re-use). It makes it easier to see the relationship between subjectivity, fashion objects and the life course and the diverse temporalities of fashion more broadly. This approach is important to an understanding of fashion as it allows us to move beyond the semiotic, and has allowed us to develop a symmetrical approach to both the cultural/ symbolic elements in fashion and the agentic elements of clothes that is needed to uncover the cultural implications of the material that makes up the surfaces that individuals present to the world.

Thinking about fashion in this way has consequences for how we approach the topic of study and also as it forces us to think about the consequences of fashion in terms of sustainability. Fashion as a system requires new things and entails the production of more things that are fashionable. It has clear consequences for materiality in terms of the mass of things that it leaves in its wake that are no longer fashionable, or through the materialities of the production of fast fashion things that are falling apart and no longer able to act as the fashionable. If attention is shifted to think about fashion through its materiality then we are forced to concentrate on the stuff we are left with.

\section{Bibliography}

Barnard, M. (ed) 2007. Fashion Theory: a Reader. London: Routledge.

Barthes, R. 1985. The Fashion System. London: Cape.

Bayly, C. 1986. 'The Origins of Swadeshi: cloth and Indian Society, 1700-1930' in Appadurai, A. The Social Life of Things. Cambridge: Cambridge University Press.

M. Bille and T. F. Sorensen, 2007, 'An Anthropology of Luminosity: the Agency of Light', Journal of Material Culture, vol. 12, no. 3, pp. 263-284

Bourdieu, P. 1977 Outline of a Theory of Practice. Cambridge: Cambridge University Press

Breward, C. 2003. Fashion. Oxford: Oxford University Press.

Breward, C. and Evans, C. (eds) 2005. Fashion and Modernity. Oxford: Berg. 
Buchli, V. (ed). 2001 The Material Culture Reader. Oxford: Berg.

Callon, M. (1986) 'Some Elements of a Sociology of Translation:

Domestication of the Scallops and the Fishermen of Saint Brieuc Bay', in J. Law (ed.) Power, Action and Belief: A New Sociology of Knowledge?, pp. 196-233. London: Routledge and Kegan Paul.

Campbell, C. 1996. 'The Meaning of Objects and the Meaning of Actions, A Critical Note on the Sociology of Consumption and Theories of Clothing' in Journal of Material Culture March 1996 vol. 1 no. 1 93-105

Chakravarti, L. 2011 'Material Worlds: Denim on the Globalised Shop Floor' Authenticity' in Woodward, S and Miller, D (eds). 2011 'Unravelling Denim' special edition of the journal Textile: the Journal of Cloth and Culture 9 (1) pp $62-75$

Entwistle, J and Slater, D. 2014. 'Reassembling the Cultural: fashion models, brands and the meaning of 'culture' after ANT' in Journal of Cultural Economy 7 (2) 161-177.

Entwistle, J. 2000. The Fashioned Body. Oxford: Polity.

Fisher, T. (2004) 'What we touch touches us: materials, affects and affordance', Design Issues, 20, 4: $20-31$

Fisher, T. (2013) 'The death and life of plastic surfaces: mobile phones', in Jennifer Gabrys, Gay Hawkins and Mike Michael (eds) Accumulation: The Material Politics of Plastic, London: Routledge pp107-121.

Maffei, N. and Fisher, T., 2013, 'Historicizing Shininess in Design: Finding Meaning in an Unstable Phenomenon', Journal of Design History, 26: 231-240

Gell, A. 1998 Art and Agency: An anthropological theory. Oxford: Oxford University Press

Gibson, J., J., 1979, The Ecological Approach to Visual Perception, New York: Houghton Mifflin

Hansen, K T 2004 'Dressing Dangerously: Mini-skirts, Gender Relations and Sexuality in Zambia' in Allman, J (ed). Fashioning Power: Clothing, Politics and African Identities. Bloomington: Indiana University Press.

Hoskins, J. 1989 'Why do Ladies Sing the Blues? Indigo Dyeing, Cloth Production and Gender Symbolism in Kodi' in

Howes, D. 2005. Empire of the Senses: the Sensual Culture Reader. Oxford: Berg. 
Ingold, T. 2007. Materials against materiality. Archaeological Dialogues 14(1): $1-16$.

Ingold, T., 2010a, 'The Textility of Making', Cambridge Journal of Economics, 34: 91-102.

Ingold, T., 2010b, 'Bringing Things to Life: Creative Entanglements in a World of Materials', Realities, Working Paper \#15.

Keane, W., 2005, 'Signs are not the Garb of Meaning: on the social analysis of material things', in in Daniel Miller (ed.) Materiality, London: Duke University Press, p.182-205.

Knappett, C., 2005, 'Materials with Materiality', Archaeological Dialogues, 14, 1: 20-23.

Küchler, S., 2005, 'Materiality and Cognition: the changing face of things', in in

Kuechler, S and Miller, D. (eds) 2005 Clothing as Material Culture. Oxford: Berg.

Latour, B. 2005. Re-assembling the social: an introduction to Actor-network theory. Oxford: Oxford University Press.

Lurie, A. 1992 The Language of Clothes. New York: Random House.

Daniel Miller (ed.) Materiality, London: Duke University Press, p. 206-230.

Magaudda, P. 2011. 'When materiality Bites back: digital music consumption practices in the age of dematerialization' in Journal of Consumer Culture 11 (1) pp 15-36

Malafouris, L., 2003. Archaeology and Dissonance: Towards a Theory of Material Engagement. Paper presented at Radical Archaeology Theory Symposium (RATS), Binghamton, New York.

Manovich, L. 2001. The Language of New Media. Boston, MA: MIT Press.

Mauss, Marcel. 1934. "Les Techniques du corps", Journal de Psychologie 32 (3-4). Reprinted in Mauss, Sociologie et anthropologie, 1936, Paris: PUF.

Miller, D., (2005) 'Materiality: An Introduction', in Daniel Miller (ed.) Materiality, London: Duke University Press, p. 1-51.

Miller, D., 2007, 'Stone Age or Plastic Age', Archaeological Dialogues, 14, 1, 23-27 
Norris, L. 2005. 'Cloth that Lies: the secrets of Recycling in India' in Kuechler, S and Miller, D. (eds) 2005 Clothing as Material Culture. Oxford: Berg.

O'Connor, K. 2005 'The Material Culture of New Fibres' in Kuechler, S and Miller, D. (eds) 2005 Clothing as Material Culture. Oxford: Berg.

Olesen, B. 2012. 'How Blue Jeans went Green: the Materiality of an American Icon' pp69-86 in Miller, D. and Woodward, S. (eds) 2012. Global Denim. Oxford: Berg.

Rocamora, A. 2011 Personal Fashion Blogs: Screens and Mirrors in Digital Self-Portraits in Fashion Theory, Volume 15, Issue 4, pp. 407-424

Simmel, G. 1971. On Individuality and Social Forms. Chicago: University of Chicago Press.

Taylor, L. 2004. Establishing Dress History. Manchester: Manchester University Press.

Thrift, N., 2005, 'Beyond Mediation: Three New Material Registers and Their Consequences', in Daniel Miller (ed.) Materiality, London: Duke University Press

Vinken, B. 2005. Fashion Zeitgeist. Oxford: Berg.

Weiner A and Schneider J (eds) 1989. Cloth and the Human Experience. London: Smithsonian Institute Press.

Wilson, E. 1985. Adorned in Dreams: Fashion and Modernity. London: Virago.

Woodward, S. 2007. Why Women Wear What they Wear. Oxford: Berg.

Woodward, S. 2009 'The Myth of the Street' in Fashion theory, March, 2009, Volume 13, no 1, pp83-102. 